\title{
New faces, similar efficacy, growing ambitions
}

\author{
Jan Deprest
}

Published online: 18 January 2013

(C) Springer-Verlag Berlin Heidelberg 2013

It is my pleasure to succeed to and to continue the work of Professor Ivo Brosens, who has been leading Gynecological Surgery in the last years. In the past, I had the privilege to work for him clinically and to collaborate with him scientifically. Now, I have accepted the challenge to follow in his footsteps and contribute to the house journal of a leading society in gynecological endoscopy. Ivo has upgraded the journal enormously. He stimulated the number of submissions, speeded up the review process, and increased the number of published papers and pages without compromising on its quality. He has pushed up the number of print subscriptions by $20 \%$ in the last 2 years, and our journal enjoyed for the last 2 years over 21,000 full article downloads yearly. Editorial work by both Ivo Brosens and Nancy Habils, as his assistant, has been swift with a tremendous turnover for submissions, with a first decision at 20 days, and final decision at 30 days. With such a track record and key figures, the Editorial Board thanked but regretted to say Ivo Brosens goodbye at the successful ESGE meeting in Paris last June.

Again, I will have difficulties to follow the track beaten by my mentor. However, the society and myself have the continuing ambition to put this journal even more visible than before on the scientific map. For that reason, the ESGE has agreed with the publisher, and the incoming Editor of your journal, to set up an expanded Editorial Office in Leuven, Belgium to manage the journal on a daily basis in the next 4 years. In total, six associated editors will conduct the scientific review of submissions, each of them in a specific field of their expertise (Table 1). Some of you have been able to meeting with them in Paris, and I am sure you will find working with them most enjoyable and productive.

J. Deprest $(\bowtie)$

University Hospital Gasthuisberg, KU Leuven, Leuven, Belgium

e-mail: Jan.Deprest@uzleuven.be
The Editor and his associates have also defined ambitious tangible goals for the journal, which have been endorsed by the ESGE. Within the term of this editorial team, the journal would like to apply for inclusion in PubMed/Medline Review. Inclusion will eventually reward you for submitting your precious work to Gynecological Surgery and make it traceable by non-ESGE fellow scientists and clinicians. Previous attempts have been increasingly successful but fell short on a number of items which the journal, its authors, and reviewers may be able to correct within the next years. The technical committee of the National Library of Medicine insisted on increasing the quality of papers. We will take for that purpose advantage of our generous Editorial Board. These board members will be asked, as an indication for their commitment, to produce swift but expert peer review. In this respect, assistance in the review process by an Associate Editor out of the field of interest will enhance that process even more. We have also slightly modified the format of some type of submissions. Formal papers will from now on always contain an abstract, which will be displayed by search engines (Table 2). Obvious additions these days are explicit disclosure on funding, ethics approval, authorship, and conflict of interest. We might be forced to cut down a bit on published short communications, though good casuistic observations may after peer review be published on the ESGE website instead, where it becomes accessible to all society members.

Further, the Associate Editors, and in the next years, Editorial Board members, will be personally responsible for generating high quality reviews and opinion articles on emerging techniques, which are of relevance to trainees as well as busy practitioners. It is their responsibility to the membership of this society. Academic board members will be prompted to submit also translational or basic research articles that are of relevance to gynecologic surgeons. We 
Table 1 Editor of Gynecological Surgery and his associates, with their field of interest and expertise. Each submission will be tagged with these categories and initially be managed by the specific editor, unless a conflict of interest
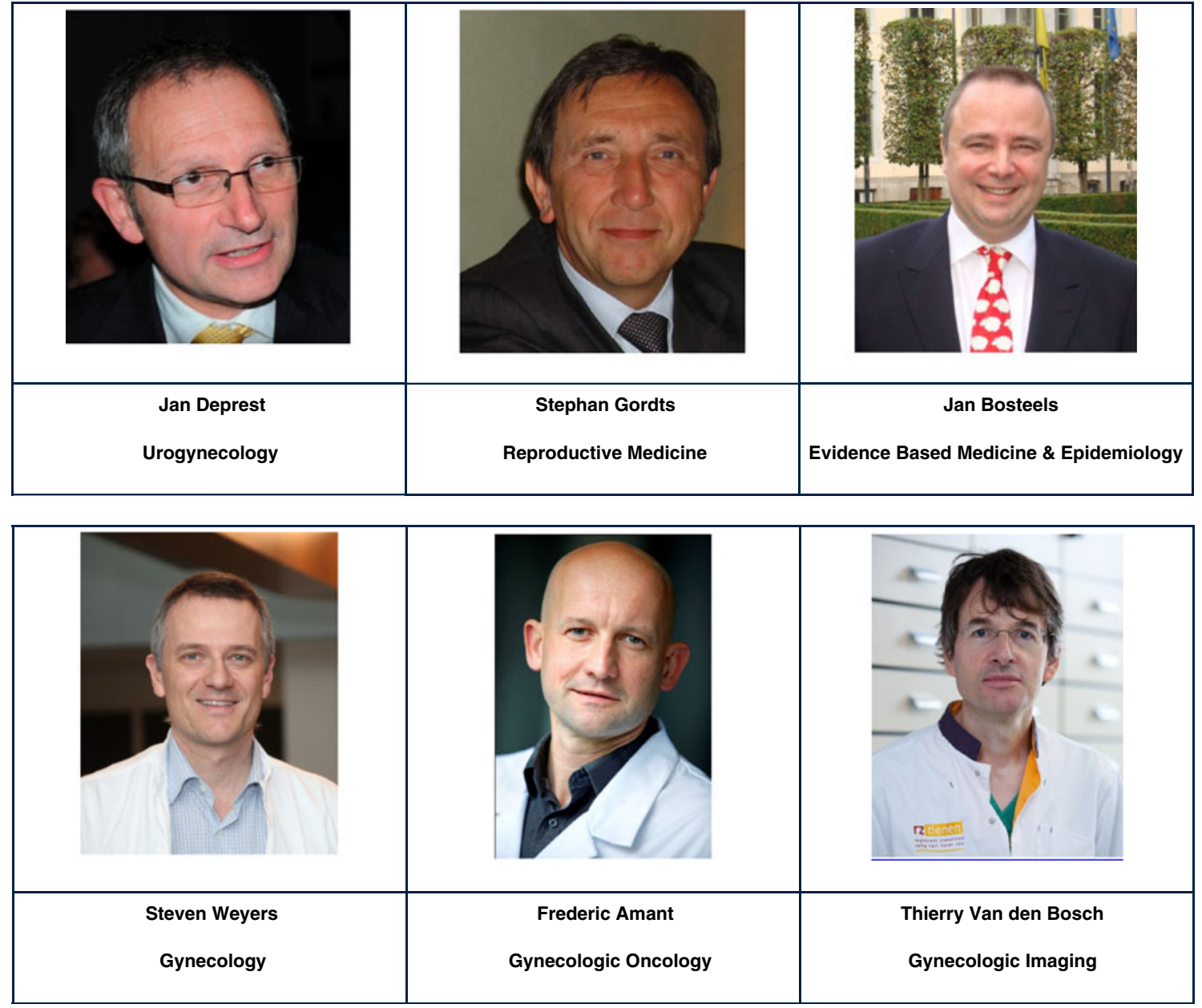

also need to expand our international coverage, and we will soon create an active international editorial board, making our journal of relevance to non-ESGE and overseas members as well. While we await inclusion, the Editorial Board will yearly grant eight papers, selected on their merits, an open access status worth $\$ 2,000$. All these initiatives should make your
Table 2 Summary format of submission types to the gynecologic surgery. Correspondence is still accepted
Original article

"Opinion"

Review Article

Techniques and instrumentation

Short communication
Title page, Abstract, Background, Method(s), Finding(s), Conclusion(s), max 50 references

Invited commentary on topics of current interest in gynecological surgery. Title, Abstract, Background, Method(s), Finding(s), Conclusion(s), 1 figure and 1 table, max 25 references, 2,500 words

Title, Abstract, Background, Method(s), Finding(s), Conclusion(s), Acknowledgements, and max 100 references

Title, Abstract, Background, Method(s), Finding(s), Conclusion(s), max 25 references, $\max 2,500$ words, max 4 authors

Title, no Abstract, Background knowledge (what is already known in max five lines), New Knowledge (what this report adds in max five lines), Finding(s), Conclusion(s), 1 figure with legend, max 7 references, 300 (image) to 500 words (case report), and max 4 authors 
submissions and subscription to Gynecological Surgery even more rewarding. I am looking forward therefore to your first submission for 2013 !
Jan Deprest, Editor-in-Chief Gynecologic Surgery, on behalf of Frederic Amant, Jan Bosteels, Stephan Gordts, Thierry Van den Bosch, and Steven Weyers, Associate Editors

\section{Gynecologic Surgery}

Has now six editors with different areas of expertise for speedy and expert peer review

Will continue to offer top quality reviews

Will select eight papers for open access per annum

Will apply for inclusion in PubMed/ Medline Review at the latest Q1/2014. 